\title{
Real-Time in Situ Monitoring of Particle and Structure Evolution in the Mechanochemical Synthesis of UiO-66 Metal-Organic Frameworks
}

Published as part of a Crystal Growth and Design virtual special issue on Crystalline Molecular Materials: From Structure to Function

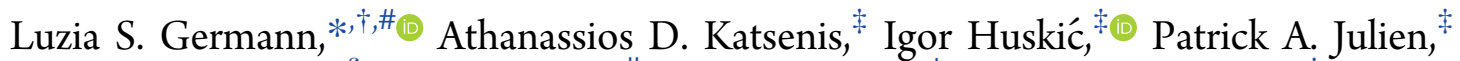

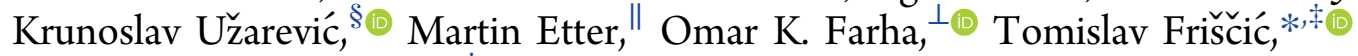
and Robert E. Dinnebier*, ${ }^{*}$

${ }^{\dagger}$ Max Planck Institute for Solid State Research, Heisenbergstrasse 1, 70569 Stuttgart, Germany

${ }^{\ddagger}$ Department of Chemistry, McGill University, 801 Sherbrooke Street W, H3A 0B8, Montreal, Canada

${ }^{\S}$ Ruđer Bošković Institute, 10000 Zagreb, Croatia

"Deutsches Elektronen-Synchrotron (DESY), 22607 Hamburg, Germany

${ }^{\perp}$ Department of Chemistry, Northwestern University, Evanston, Illinois 60208, United States

\section{Supporting Information}

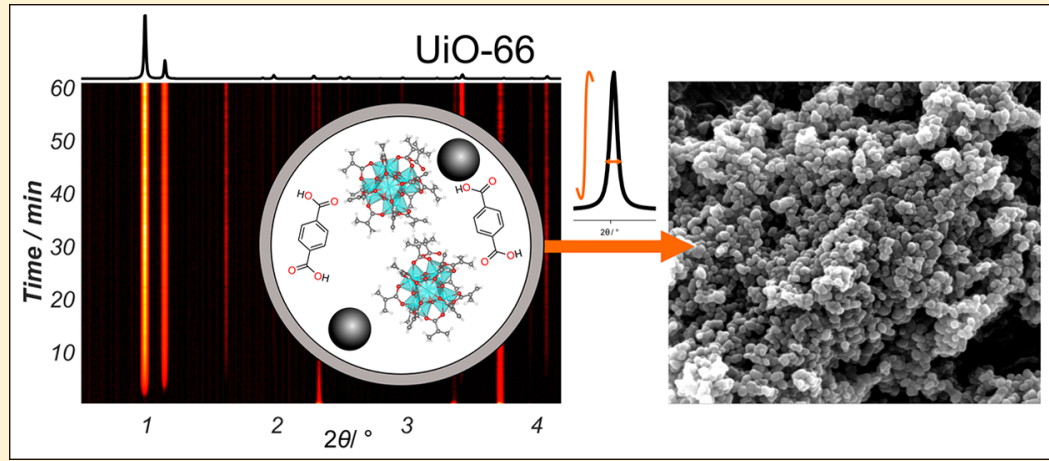

ABSTRACT: While in situ synchrotron X-ray powder diffraction has revolutionized mechanistic studies of mechanochemistry and inspired the development of other real-time monitoring approaches, the full potential of such data remains unexploited, with most applications addressing only reaction kinetics. Focusing on UiO-type metal-organic frameworks (MOFs) as models, we now show how in-depth analysis of real-time diffraction data can provide insight into the evolution of both crystallographic structure and crystallite size, including the direct relation to the particle size of mechanochemically formed MOFs.

$\mathrm{T}^{\mathrm{h}}$ he growing applications of mechanochemistry in molecular and materials syntheses have inspired the emergence of increasingly sophisticated tools for real-time observation of mechanochemical reactions. ${ }^{1-3}$ Examples of these include tandem reaction monitoring by Raman spectroscopy and powder X-ray diffraction (PXRD), or combined PXRD and thermal measurements. ${ }^{4-9}$ However, PXRD alone offers a plethora of information that has not yet been exploited in reports of in situ studies, which usually stay limited to qualitative analysis of reaction kinetics, neglecting structural and microstructural changes, such as the evolution of lattice parameters and crystallite size. ${ }^{10,11}$

Here, using as a model reaction the mechanochemical synthesis of a highly stable UiO-type metal-organic framework (MOF), we provide a detailed, real-time analysis of the product structure and particle size during mechanosynthesis, revealing a previously not reported framework flexibility of the product structure in the early stage of the reaction. Moreover, a direct relation between crystallite size and actual particle size was established. We chose as our model UiO-66, ${ }^{12-14}$ a fcutopology MOF based on hexanuclear zirconium hydroxoclusters as nodes and terephthalate linkers, due to its demonstrated chemical and thermal stability to a variety of conditions. ${ }^{13,15}$ We have previously shown that microporous UiO-66 and its isostructural amino-derivative $\mathrm{UiO}-66-\mathrm{NH}_{2}$ can be readily synthesized by liquid-assisted grinding (LAG), a mechanochemical technique in which the reactants are milled in the presence of a small amount of a liquid additive, of

Received: November 3, 2019

Published: November 15, 2019 
preassembled zirconium clusters with either terephthalic $\left(\mathrm{H}_{2} \mathrm{TPA}\right)$ or 2-aminoterephthalic acid $\left(\mathrm{H}_{2} \mathrm{TPA}-\mathrm{NH}_{2}\right)$, respectively. ${ }^{16,17}$

We now show how in situ data can be used to extract detailed information on the development of product structure and microstructure during the LAG synthesis of UiO-66 and UiO-66- $\mathrm{NH}_{2}$ by using in situ PXRD data. All reactions were conducted by milling the preassembled methacrylate cluster $\mathrm{Zr}_{6} \mathrm{O}_{4}(\mathrm{OH})_{4}\left(\mathrm{C}_{3} \mathrm{H}_{5} \mathrm{CO}_{2}\right)_{12}(\mathrm{Zr6M})$ with $\mathrm{H}_{2}$ TPA or $\mathrm{H}_{2}$ TPA$\mathrm{NH}_{2}$ in the respective 1:6 stoichiometric ratio (Figure 1a). Reactions were performed using either methanol $(\mathrm{MeOH})$ or $\mathrm{N}, \mathrm{N}$-dimethylformamide (DMF) as the liquid additive with $\eta,{ }^{18}$ the ratio of liquid volume to reactant weight, in the range between $0.5 \mu \mathrm{L} / \mathrm{mg}$ and $0.78 \mu \mathrm{L} / \mathrm{mg}$ (Table 1). Reactions were performed in a poly(methyl methacrylate) (PMMA) jar mounted on a modified Retsch MM400 mill operating at 30 $\mathrm{Hz}$, using stainless steel milling media. Real-time monitoring was conducted at the Deutsches Elektronen-Synchrotron (DESY) P02.1 beamline using an energy of $60 \mathrm{keV}(\lambda=$ $0.207 \AA$ ) with a time resolution of $10 \mathrm{~s}$.

Analysis of in situ PXRD data shows that the formation of UiO-66 by LAG with $\mathrm{MeOH}(\eta=0.78 \mu \mathrm{L} / \mathrm{mg})$, using a single stainless steel ball of $9 \mathrm{~mm}$ diameter ( $3.5 \mathrm{~g}$ weight), proceeds without any crystalline intermediates, with the diffraction signals of the MOF appearing within 2 min from the onset of milling (Figure 1b). A qualitative assessment of the product formation and reaction progress was accomplished by integrating the intensity of the first, most prominent X-ray reflection (111) at $2 \theta=0.99^{\circ}$. Such analysis is less sensitive to absorption of X-rays by the milling media, which is strongly

(a)
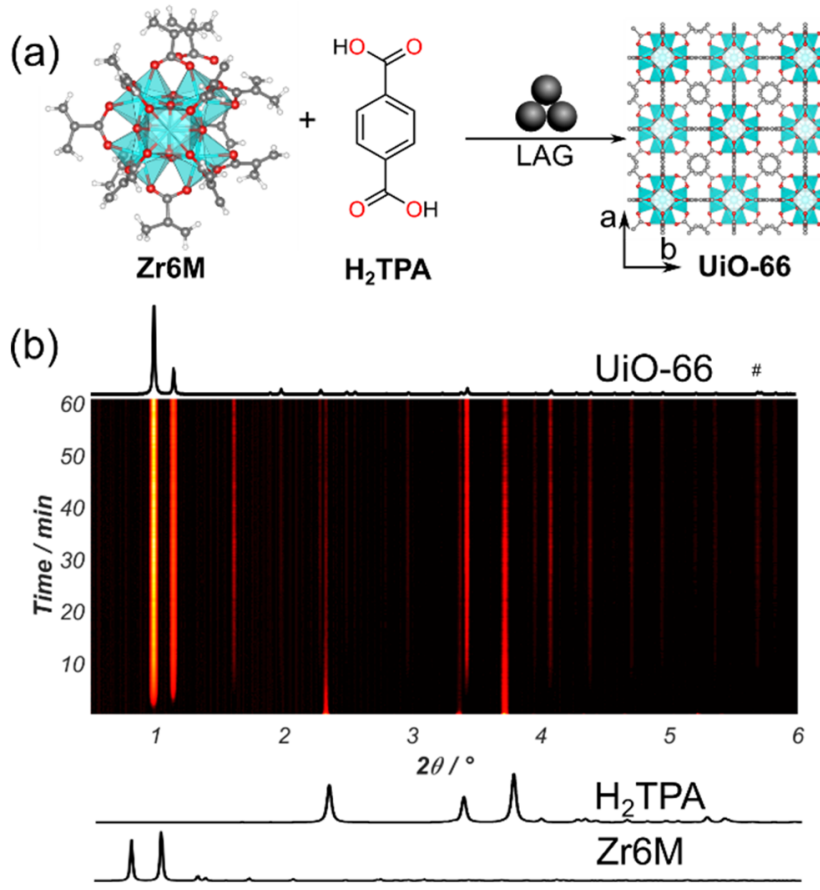

Figure 1. (a) Scheme of mechanochemical UiO-66 synthesis; (b) time-resolved $2 \mathrm{D}$ diffraction plot for the LAG reaction using $\mathrm{MeOH}$ $\left(\eta=0.78 \mu \mathrm{L} / \mathrm{mg}\right.$ ), with calculated PXRD patterns of $\mathrm{H}_{2}$ TPA (CSD code TEPHTH), Zr6M (CSD code REBNUH), and UiO-66 (CSD code RUBTAK) shown below and above the plot. The diffraction signal of the steel balls is marked with "\#”.
Table 1. Selected Parameters for Herein Explored in Situ Monitoring Experiments

\begin{tabular}{lclc}
\multicolumn{1}{c}{ MOF } & Zr6M & LAG additive & $\eta[\mu \mathrm{L} / \mathrm{mg}]$ \\
UiO-66 & $161.8 \mathrm{mg}$ & $\mathrm{MeOH}, 200 \mu \mathrm{L}$ & 0.78 \\
$\mathrm{UiO}-66^{a}$ & $161.9 \mathrm{mg}$ & $\mathrm{MeOH}, 170 \mu \mathrm{L}$ & 0.71 \\
$\mathrm{UiO}-66$ & $189.1 \mathrm{mg}$ & $\mathrm{DMF}, 150 \mu \mathrm{L}$ & 0.5 \\
$\mathrm{UiO}-66-\mathrm{NH}_{2}$ & $183.2 \mathrm{mg}$ & $\mathrm{MeOH}, 200 \mu \mathrm{L}$ & 0.66 \\
$\mathrm{UiO}-66-\mathrm{NH}_{2}$ & $183.1 \mathrm{mg}$ & $\mathrm{DMF}, 200 \mu \mathrm{L}$ & 0.66
\end{tabular}

${ }^{a}$ Milled with the addition of $8.9 \mathrm{w} \%$ silicon as an internal standard.

(a)

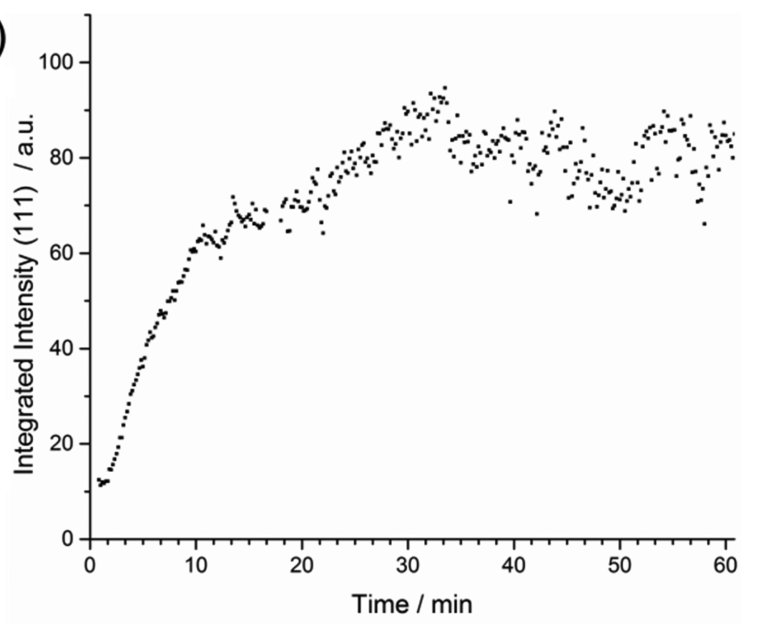

(b)

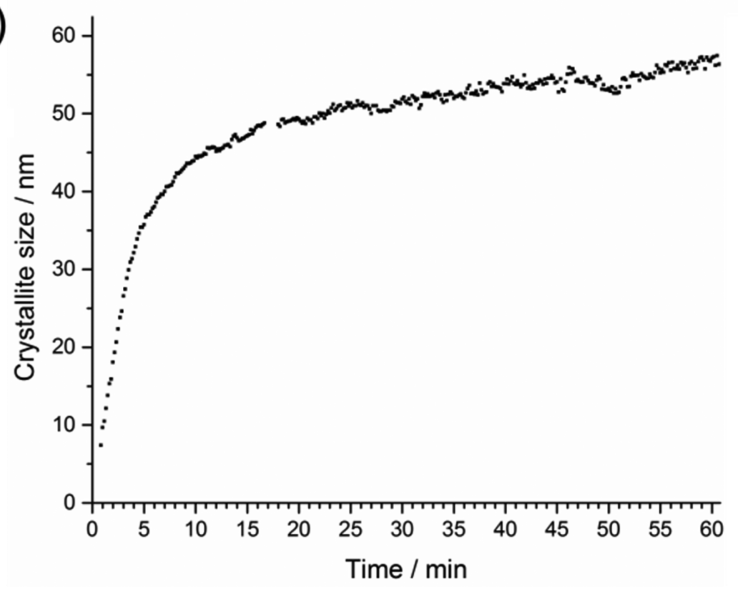

Figure 2. (a) Changes in the integrated peak intensity of the most prominent Bragg reflection (111), $2 \theta=0.99^{\circ}$, over time. (b) Evolution of crystallite size of UiO-66 synthesized by LAG with $\mathrm{MeOH}$ over time.

fluctuating because the dwell time of the moving balls in the Xray illuminated area is not constant, and also due to changes in the pore content of the nascent MOF over time. Both effects influence the absolute intensities, making Rietveld refinement challenging. Analysis of the integrated peak intensity of the (111) reflection revealed that the amount of crystalline UiO-66 rapidly increased in the first $15 \mathrm{~min}$ of milling, after which it leveled off to a steady value within ca. $40 \mathrm{~min}$ (Figure 2a).

Next, we used the Scherrer method to evaluate changes in crystallite size during the mechanochemical reaction. ${ }^{19,20}$ Whereas the UiO-materials are well-known for their propensity for different types of defects, for example, missing linkers, ${ }^{21-23}$ the in situ milling PXRD data are generally not of sufficient quality to reliably establish the presence or absence of such defects. The instrumental profile function (IPF) was 
(a)

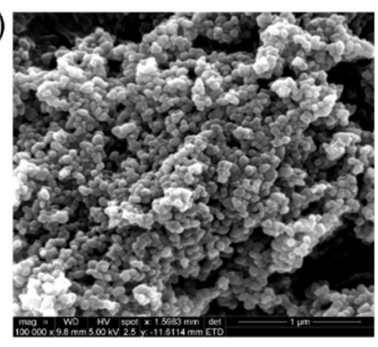

(c)

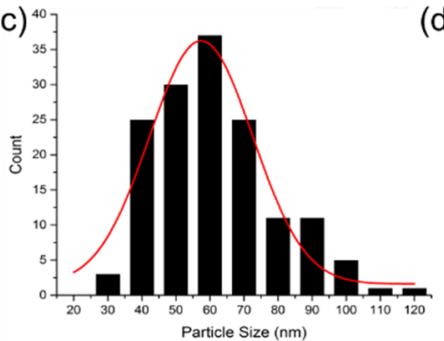

(b)

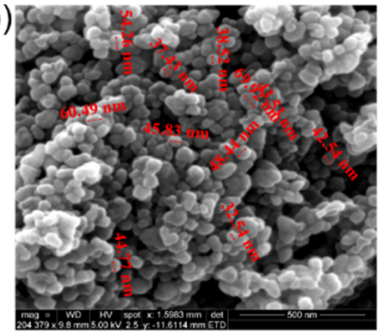

(d)

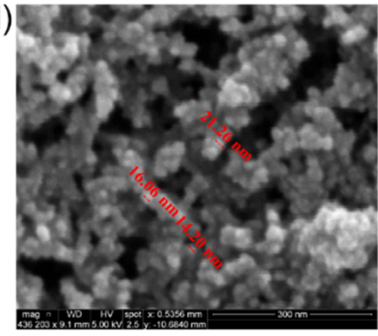

Figure 3. (a, b) Representative SEM images for UiO-66 synthesized using $\mathrm{MeOH}$ as LAG additive, $\eta=0.78 \mu \mathrm{L} / \mathrm{mg}$ with different magnifications and particle sizes labeled in (b). (c) Related particle size distribution derived by measuring the size of $150 \mathrm{MOF}$ particles. (d) Representative SEM image for UiO-66 synthesized using DMF as LAG additive, $\eta=0.5 \mu \mathrm{L} / \mathrm{mg}$.

determined with the help of a silicon standard, which was separately measured in an otherwise empty, oscillating milling jar, and subsequently deconvoluted from the measured profile. A similar approach was previously applied to determine the average crystallite size and dislocation density for ceramic powders treated by ball milling. ${ }^{24,25}$ The crystallite size was obtained by taking the integral breadth of the Bragg reflections and assuming spherical particles, since the UiO-66 structure exhibits a cubic symmetry and the milling process is not expected to lead to any preferential growth directions. Importantly, while microstrain could play a role in the interpretation of the data, we have opted not to include it throughout this analysis, since attempts of simultaneous refinement led to a high correlation between microstrain and crystallite size, with subsequent decomposition being hindered due to an insufficient number of reflections. Importantly, the refinement with only crystallite size led to an equally good fit.

The above-described approach indicated a rapid increase of the average calculated crystallite size up to ca. $50 \mathrm{~nm}$ in the first $15 \mathrm{~min}$ of milling, after which the increase in calculated crystallite size is significantly slower, reaching ca. $60 \mathrm{~nm}$ after $60 \mathrm{~min}$ (Figure 2b). To validate the results of Scherrer analysis, the reaction was repeated in a conventional laboratory setting, and the particle sizes were analyzed by scanning electron microscopy (SEM), on samples that were washed with hexanes immediately after milling and then dispersed through sonication to avoid agglomeration. Imaging of samples prepared in that way using SEM revealed roughly roundshaped particles with a size range of $32-70 \mathrm{~nm}$ (Figure 3a,b, Supporting Information), with an average particle size of ca. 57 $\mathrm{nm}$ (Figure 3c). While the observed particle size does not necessarily need to correspond to the crystallite sizes calculated using the Scherrer approach, the obtained numbers are in good agreement with the average crystallite size obtained from the in situ PXRD analysis, validating the applicability of the Scherrer method (Figure 2b) for time-resolved monitoring (Figure 3).

The reaction was repeated with slightly modified parameters $(\eta=0.71 \mu \mathrm{L} / \mathrm{mg})$, using ca. $10 \mathrm{wt} \%$ of silicon as an internal

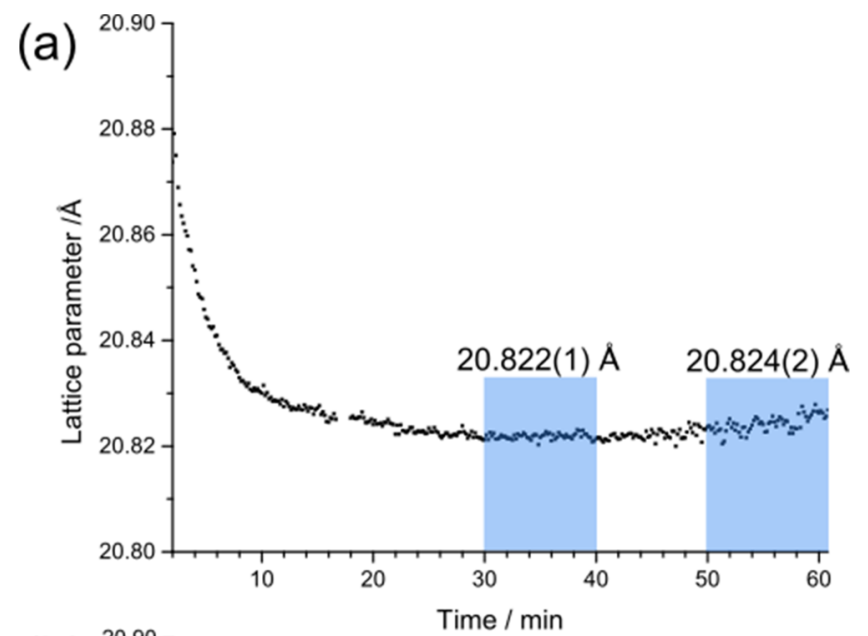

(b)
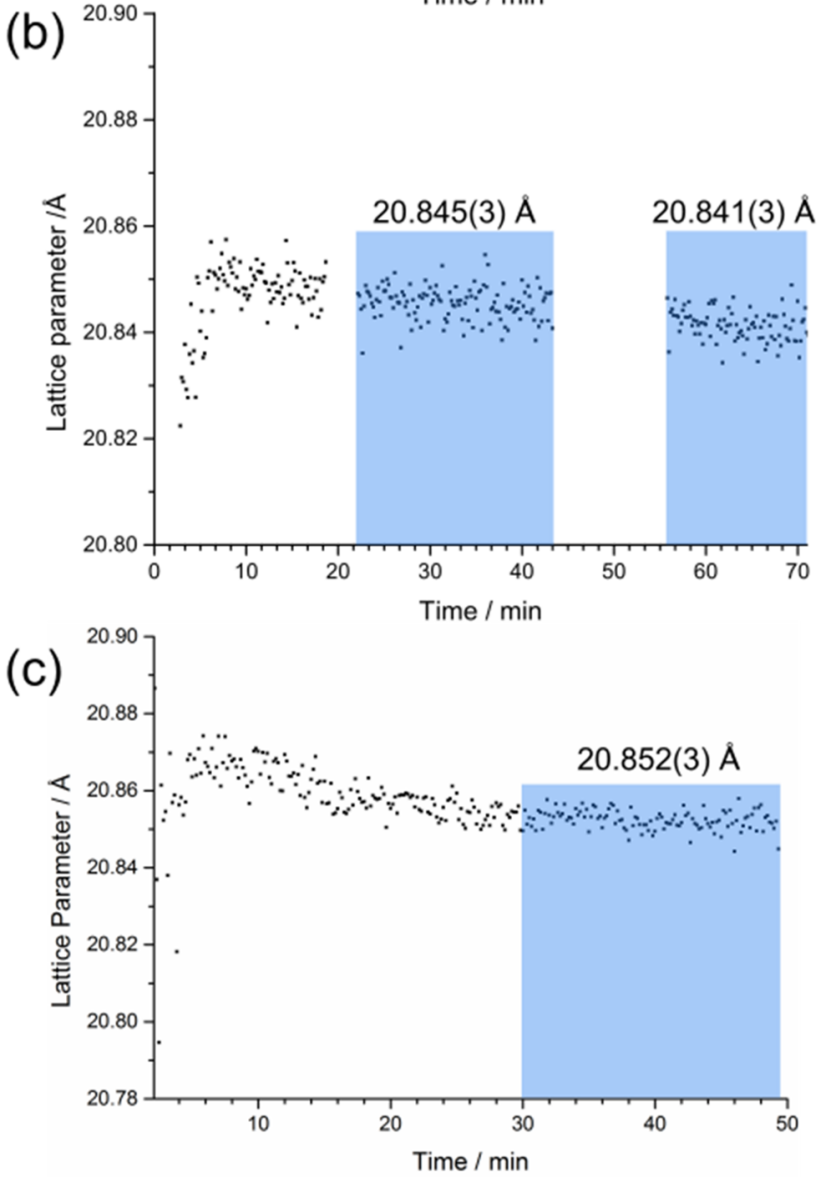

Figure 4. Evolution of the cubic UiO-66 lattice parameter $a$ as a function of LAG reaction time for (a) $\mathrm{MeOH}(\eta=0.78 \mu \mathrm{L} / \mathrm{mg}),(\mathrm{b})$ DMF $(\eta=0.5 \mu \mathrm{L} / \mathrm{mg})$, and (c) $\mathrm{UiO}-66-\mathrm{NH}_{2}$ with $\mathrm{MeOH}(\eta=0.66$ $\mu \mathrm{L} / \mathrm{mg}$ ) as the LAG additive. The shutter of the beamline closed accidentally during the data collection of the reaction using DMF as a LAG additive, evidenced by the absence of diffraction signal around 18-22 $\mathrm{min}$ and $43-55 \mathrm{~min}$. The first part of the reactions was omitted as it took several scans until UiO-66 started forming. The increase in crystallite size and intensity of the (111) reflection were taken as a measure of when UiO-66 started forming. The lattice parameters $a$ were averaged over the blue areas.

diffraction standard, with two stainless steel balls of $7 \mathrm{~mm}$ diameter as milling media ( $1.3 \mathrm{~g}$ each). The general reaction outcome was similar as for the above-mentioned reaction. 
However, the reaction showed a transient induction period of about $10 \mathrm{~min}$ (Figures $\mathrm{S} 1-\mathrm{S} 4$ in the Supporting Information).

Next, we performed the reaction with DMF as the LAG additive. While this reaction also proceeded without any observable crystalline intermediates (see Figure S5), the presence of a different LAG additive slowed the reaction and led to a time delay, with the product $\mathrm{X}$-ray reflections appearing only after ca. 5 min of milling. The integrated peak intensity of the (111) Bragg reflection of UiO-66 revealed rapid product formation within the first 10 min of milling, after which a plateau is reached (Figure S6). The Scherrer analysis revealed a continuous increase in crystallite size, reaching a value of approximately $10 \mathrm{~nm}$ after $55 \mathrm{~min}$ (Figure S7). SEM analysis of the UiO-66 materials synthesized mechanochemically by LAG with DMF revealed particles with sizes in the range of 9-20 nm (Figure S14), which is again in very good agreement with the average crystallite size obtained by Scherrer analysis of in situ PXRD data. The improved crystallinity of UiO-66 obtained by LAG with $\mathrm{MeOH}$, compared to the material obtained in the presence of DMF, is consistent with previous work. ${ }^{16}$ The ability to monitor in situ and in real time the evolution of crystallite or particle size is of particular interest, since it has been shown that changes of crystallite size can alter the physical properties of a material, such as stiffness ${ }^{26}$ or lead to polymorphic transitions. ${ }^{27}$

In principle, the in situ monitoring technique not only enables the continuous observation of the crystallite size evolution and the extent of reaction, but can also provide insights into the development of product structure. ${ }^{25}$ Such structural development is a complex phenomenon, potentially including changes at the level of the crystal structure, e.g., framework flexibility, as well as changes in the microstructure. As the first entry into in situ investigations of such structural development upon milling, we have monitored changes in the lattice parameter $(a)$ and unit cell volume $(V)$ of cubic UiO-66 during its LAG synthesis. The analysis revealed unexpected flexibility of the nascent MOF structures, which was also strongly affected by the choice of milling liquid. The lattice parameter $a$ of UiO-66 consistently decreased in the early stages of LAG synthesis with $\mathrm{MeOH}$, independent of the other experimental conditions (Figures $4 \mathrm{a}$ and S4). Specifically, $a$ decreased from $20.88 \AA$ to $20.824(2) \AA$ for $\eta=0.78 \mu \mathrm{L} / \mathrm{mg}$ and to $20.805(2)$ for $\eta=0.71 \mu \mathrm{L} / \mathrm{mg}$, respectively. In contrast, LAG reactions with DMF displayed an initial increase in a, followed by a slight decrease to the final value of 20.844(4) $\AA$ for $\eta=0.5 \mu \mathrm{L} / \mathrm{mg}$ (Figure $4 \mathrm{~b}$ ). We believe that this unexpected behavior reflects a high degree of structural flexibility in nanosized MOF crystals existing in early stages of the reaction. While the increase and drop in $a$ value, observed in case of reactions involving DMF, can not yet be readily explained, we note that the appearance of a structure with a larger $a$ parameter in the early stages of LAG with $\mathrm{MeOH}$ is reminiscent of previously observed mechanisms of MOF formation, ${ }^{1,2,28}$ where lower density polymorphs appear first. Interestingly, the UiO-66 lattice parameters observed from in situ data are slightly but significantly higher than any previously reported from single crystal structure measurements on either defective or defect-free samples, which typically range between 20.66 and $20.76 \AA$ (see Table S2 for overview). As single crystal data are typically based on materials obtained via solution-based syntheses using $\mathrm{ZrCl}_{4}$ or $\mathrm{ZrOCl}_{2}$ as the zirconium source, this observation suggests that both the synthesis method (mechanochemistry or solution-based syn- thesis) and the choice of zirconium precursor $\left(\mathrm{ZrCl}_{4}\right.$ vs $\left.\mathrm{Zr6M}\right)$ can have a previously not recognized impact on crystallographic parameters of the final MOF structure.

We also explored the LAG formation of UiO-66- $\mathrm{NH}_{2}$ using either $\mathrm{MeOH}$ or DMF as liquid additives $(\eta=0.66 \mu \mathrm{L} / \mathrm{mg})$. As observed for UiO-66, milling of $\mathrm{Zr6M}$ with $\mathrm{H}_{2} \mathrm{TPA}-\mathrm{NH}_{2}$ leads directly to the $\mathrm{UiO}-66-\mathrm{NH}_{2}$ product (CSD code EWILIH) without any observable crystalline intermediate (Figures S8 and S11). However, the product was found not to be as highly crystalline as UiO-66, as evidenced by the lower intensity and larger width of Bragg reflections. Tentatively, this might be related to the known disorder ${ }^{29}$ of the amino group in the crystal structure. Analysis of the behavior of lattice parameter $a$ as a function of milling time indicates a similar trend as observed in the LAG formation of UiO-66 with DMF (Figure $4 b, c)$. A comparison of the diffraction signals for both LAG reactions (using $\mathrm{MeOH}$ or DMF) indicates that the crystallinity is again higher for the reaction involving $\mathrm{MeOH}$ as the LAG additive.

In conclusion, we have used in situ X-ray diffraction monitoring to extract previously unused information on the development of product structure in the early stages of a mechanochemical reaction. The comparison of results of Scherrer analysis of in situ data to SEM imaging revealed an excellent match of the average sizes, demonstrating that realtime diffraction studies permit assessment of the development of product crystallite size during mechanochemical formation of MOFs. Such monitoring also allowed novel insight into the evolution of the product crystal structures in early stages of mechanosynthesis, as seen from a previously not observed effect of milling liquid on the cubic lattice parameter of both $\mathrm{UiO}-66$ and $\mathrm{UiO}-66-\mathrm{NH}_{2}$ : while a significant lattice contraction was observed for reactions involving $\mathrm{MeOH}$ as the LAG additive, the framework structure underwent slight expansion, followed by contraction, when DMF was used. Furthermore, the cell parameters derived from the in situ analysis were, also unexpectedly, found to be slightly larger than most of those reported in the literature. These results suggest that both the used zirconium precursor and the choice of synthesis route may have a strong influence on the final MOF structures and the crystallite size. We believe that the presented results open new opportunities for understanding mechanochemical reactions through in situ X-ray diffraction, with importance in developing both mechanochemistry and especially routes to MOF materials with targeted particle sizes.

\section{ASSOCIATED CONTENT}

\section{S Supporting Information}

The Supporting Information is available free of charge at https://pubs.acs.org/doi/10.1021/acs.cgd.9b01477.

Details of experiments, in situ PXRD analysis, and SEM experiments. In addition, a table summarizing all hitherto reported lattice parameters for the UiO-66 MOF (PDF)

\section{AUTHOR INFORMATION}

\section{Corresponding Authors}

*E-mail: luzia.germann@gmail.com (L.S.G).

*E-mail: tomislav.friscic@mcgill.ca (T.F).

*E-mail: robert.dinnebier@fkf.mpg.de (R.E.D).

ORCID

Luzia S. Germann: 0000-0003-1760-5842 
Igor Huskić: 0000-0003-1011-1460

Krunoslav Užarević: 0000-0002-7513-6485

Omar K. Farha: 0000-0002-9904-9845

Tomislav Frǐ̌čić: 0000-0002-3921-7915

\section{Present Address}

\#(L.S.G.) Department of Chemistry, McGill University, 801 Sherbrooke St. W., H3A 0B8, Montreal, Canada

\section{Notes}

The authors declare no competing financial interest.

\section{ACKNOWLEDGMENTS}

We thank Dr. Ivan Halasz for helpful discussions. This work has been supported by the Croatian Science Foundation (Grant 4744). O.K.F. gratefully acknowledges support from the Defense Threat Reduction Agency (HDTRA1-18-1-0003). L.S.G. acknowledges financial support from the Swiss National Science Foundation (Grant P2SKP2_187638). K.U. and T.F. acknowledge support from the Croatian Science Foundation and European Social Fund (Grant PZS-2019-02-4129). T.F. acknowledges the financial support of the NSERC Discovery Grant (RGPIN-2017-06467), NSERC Discovery Accelerator Award (RGPAS 507837-17), and the NSERC E. W. R. Steacie Memorial Fellowship (SMFSU 507347-17). The authors would like to acknowledge networking support by the COST Action CA18112 - Mechanochemistry for Sustainable Industry (www.mechsustind.eu) supported by COST (European Cooperation in Science and Technology, www.cost.eu).

\section{REFERENCES}

(1) Frǐ̌čić, T.; Halasz, I.; Beldon, P. J.; Belenguer, A. M.; Adams, F.; Kimber, S. A. J.; Honkimaki, V.; Dinnebier, R. E. Real-time and in situ monitoring of mechanochemical milling reactions. Nat. Chem. 2013, 5, 66-73.

(2) Užarević, K.; Halasz, I.; Friščić, T. Real-Time and In Situ Monitoring of Mechanochemical Reactions: A New Playground for All Chemists. J. Phys. Chem. Lett. 2015, 6, 4129-4140.

(3) Ban, V.; Sadikin, Y.; Lange, M.; Tumanov, N.; Filinchuk, Y.; Cerný, R.; Casati, N. Innovative in Situ Ball Mill for X-ray Diffraction. Anal. Chem. 2017, 89, 13176-13181.

(4) Lukin, S.; Stolar, T.; Tireli, M.; Blanco, M. V.; Babić, D.; Friščić, T.; Užarević, K.; Halasz, I. Tandem In Situ Monitoring for Quantitative Assessment of Mechanochemical Reactions Involving Structurally Unknown Phases. Chem. - Eur. J. 2017, 23, 13941-13949.

(5) Kulla, H.; Wilke, M.; Fischer, F.; Röllig, M.; Maierhofer, C.; Emmerling, F. Warming up for mechanosynthesis - temperature development in ball mills during synthesis. Chem. Commun. 2017, 53, 1664-1667.

(6) Kulla, H.; Haferkamp, S.; Akhmetova, I.; Röllig, M.; Maierhofer, C.; Rademann, K.; Emmerling, F. In Situ Investigations of Mechanochemical One-Pot Syntheses. Angew. Chem., Int. Ed. 2018, 57, 5930-5933.

(7) Batzdorf, L.; Fischer, F.; Wilke, M.; Wenzel, K. J.; Emmerling, F. Direct In Situ Investigation of Milling Reactions Using Combined Xray Diffraction and Raman Spectroscopy. Angew. Chem., Int. Ed. 2015, 54, 1799-1802.

(8) Tumanova, N.; Tumanov, N.; Robeyns, K.; Fischer, F.; Fusaro, L.; Morelle, F.; Ban, V.; Hautier, G.; Filinchuk, Y.; Wouters, J.; Leyssens, T.; Emmerling, F. Opening Pandora's Box: Chirality, Polymorphism, and Stoichiometric Diversity in Flurbiprofen/Proline Cocrystals. Cryst. Growth Des. 2018, 18, 954-961.

(9) Užarević, K.; Ferdelji, N.; Mrla, T.; Julien, P. A.; Halasz, B.; Friščić, T.; Halasz, I. Enthalpy vs. friction: heat flow modelling of unexpected temperature profiles in mechanochemistry of metalorganic frameworks. Chem. Sci. 2018, 9, 2525-2532.
(10) Halasz, I.; Puškarić, A.; Kimber, S. A. J.; Beldon, P. J.; Belenguer, A. M.; Adams, F.; Honkimäki, V.; Dinnebier, R. E.; Patel, B.; Jones, W.; Strukil, V.; Friščić, T. Real-time In Situ Powder X-ray Diffraction Monitoring of Mechanochemical Synthesis of Pharmaceutical Cocrystals. Angew. Chem., Int. Ed. 2013, 52, 11538-11541.

(11) Delogu, F.; Takacs, L. Information on the mechanism of mechanochemical reaction from detailed studies of the reaction kinetics. J. Mater. Sci. 2018, 53, 13331-13342.

(12) Cavka, J. H.; Jakobsen, S.; Olsbye, U.; Guillou, N.; Lamberti, C.; Bordiga, S.; Lillerud, K. P. A New Zirconium Inorganic Building Brick Forming Metal Organic Frameworks with Exceptional Stability. J. Am. Chem. Soc. 2008, 130, 13850-13851.

(13) Kandiah, M.; Nilsen, M. H.; Usseglio, S.; Jakobsen, S.; Olsbye, U.; Tilset, M.; Larabi, C.; Quadrelli, E. A.; Bonino, F.; Lillerud, K. P. Synthesis and Stability of Tagged UiO-66 Zr-MOFs. Chem. Mater. 2010, 22, 6632-6640.

(14) Katz, M. J.; Brown, Z. J.; Colón, Y. J.; Siu, P. W.; Scheidt, K. A.; Snurr, R. Q.; Hupp, J. T.; Farha, O. K. A facile synthesis of UiO-66, UiO-67 and their derivatives. Chem. Commun. 2013, 49, 9449-9451.

(15) Ryu, S. G.; Kim, M.-K.; Park, M.; Jang, S. O.; Kim, S. H.; Jung, $\mathrm{H}$. Availability of $\mathrm{Zr}$-Based MOFs for the degradation of nerve agents in all humidity conditions. Microporous Mesoporous Mater. 2019, 274, $9-16$.

(16) Užarević, K.; Wang, T. C.; Moon, S.-Y.; Fidelli, A. M.; Hupp, J. T.; Farha, O. K.; Friščić, T. Mechanochemical and solvent-free assembly of zirconium-based metal-organic frameworks. Chem. Commun. 2016, 52, 2133-2136.

(17) Karadeniz, B.; Howarth, A. J.; Stolar, T.; Islamoglu, T.; Dejanović, I.; Tireli, M.; Wasson, M. C.; Moon, S.-Y.; Farha, O. K.; Friščić, T.; Užarević, K. Benign by Design: Green and Scalable Synthesis of Zirconium UiO- Metal-Organic Frameworks by WaterAssisted Mechanochemistry. ACS Sustainable Chem. Eng. 2018, 6, 15841-15849.

(18) Friščić, T.; Childs, S. L.; Rizvi, S. A. A.; Jones, W. The role of solvent in mechanochemical and sonochemical cocrystal formation: a solubility-based approach for predicting cocrystallisation outcome. CrystEngComm 2009, 11, 418-426.

(19) Langford, J. I.; Wilson, A. J. C. Scherrer after Sixty Years: A Survey and Some New Results in the Determination of Crystallite Size. J. Appl. Crystallogr. 1978, 11, 102-113.

(20) Scardi, P.; Leoni, M.; Delhez, R. Line broadening analysis using integral breadth methods: a critical review. J. Appl. Crystallogr. 2004, 37, 381-390.

(21) Valenzano, L.; Civalleri, B.; Chavan, S.; Bordiga, S.; Nilsen, M. H.; Jakobsen, S.; Lillerud, K. P.; Lamberti, C. Disclosing the Complex Structure of UiO-66 Metal Organic Framework: A Synergic Combination of Experiment and Theory. Chem. Mater. 2011, 23, 1700-1718.

(22) Cliffe, M. J.; Wan, W.; Zou, X.; Chater, P. A.; Kleppe, A. K.; Tucker, M. G.; Wilhelm, H.; Funnell, N. P.; Coudert, F.-X.; Goodwin, A. L. Correlated defect nanoregions in a metal-organic framework. Nat. Commun. 2014, 5, 4176.

(23) Rogge, S. M. J.; Wieme, J.; Vanduyfhuys, L.; Vandenbrande, S.; Maurin, G.; Verstraelen, T.; Waroquier, M.; Van Speybroeck, V. Thermodynamic Insight in the High-Pressure Behavior of UiO-66: Effect of Linker Defects and Linker Expansion. Chem. Mater. 2016, $28,5721-5732$.

(24) Broseghini, M.; Gelisio, L.; D’Incau, M.; Azanza Ricardo, C. L.; Pugno, N. M.; Scardi, P. Modeling of the planetary ball-milling process: The case study of ceramic powders. J. Eur. Ceram. Soc. 2016, $36,2205-2212$.

(25) Tagliazucca, V.; Leoni, M.; Weidenthaler, C. Crystal structure and microstructure changes of molybdenum nitrides traced during reaction by in situ X-ray diffraction studies. Phys. Chem. Chem. Phys. 2014, 16, 6182-6188.

(26) Tiba, A. A.; Tivanski, A. V.; MacGillivray, L. R. Size-Dependent Mechanical Properties of a Metal-Organic Framework: Increase in Flexibility of ZIF-8 by Crystal Downsizing. Nano Lett. 2019, 19, 6140-6143. 
(27) Belenguer, A. M.; Lampronti, G. I.; Cruz-Cabeza, A. J.; Hunter, C. A.; Sanders, J. K. M. Solvation and surface effects on polymorph stabilities at the nanoscale. Chem. Sci. 2016, 7, 6617-6627.

(28) Katsenis, A. D.; Puškarić, A.; Štrukil, V.; Mottillo, C.; Julien, P. A.; Užarević, K.; Pham, M.-H.; Do, T.-O.; Kimber, S. A. J.; Lazić, P.; Magdysyuk, O.; Dinnebier, R. E.; Halasz, I.; Friščić, T. In situ X-ray diffraction monitoring of a mechanochemical reaction reveals a unique topology metal-organic framework. Nat. Commun. 2015, 6, 6662.

(29) Banerjee, D.; Xu, W.; Nie, Z.; Johnson, L. E. V.; Coghlan, C.; Sushko, M. L.; Kim, D.; Schweiger, M. J.; Kruger, A. A.; Doonan, C. J.; Thallapally, P. K. Zirconium-Based Metal-Organic Framework for Removal of Perrhenate from Water. Inorg. Chem. 2016, 55, 82418243. 